Portland State University

PDXScholar

\title{
Women and the Wilderness: a Review of Barriers to Participation, Current Coping Strategies, and Guidance for Future Programs
}

Naiyear Khajavei

Portland State University

Follow this and additional works at: https://pdxscholar.library.pdx.edu/honorstheses

Let us know how access to this document benefits you.

\section{Recommended Citation}

Khajavei, Naiyear, "Women and the Wilderness: a Review of Barriers to Participation, Current Coping Strategies, and Guidance for Future Programs" (2017). University Honors Theses. Paper 462.

https://doi.org/10.15760/honors.459

This Thesis is brought to you for free and open access. It has been accepted for inclusion in University Honors Theses by an authorized administrator of PDXScholar. Please contact us if we can make this document more accessible: pdxscholar@pdx.edu. 
Khajavei, 1

\title{
Women and the Wilderness; a Review of Barriers to Participation, Current \\ Coping Strategies, and Guidance for Future Programs
}

\author{
By: Naiyear L. Khajavei \\ An undergraduate honors thesis submitted in partial fulfillment of the \\ requirements for the degree of \\ Bachelor of Science \\ in \\ University Honors \\ and \\ Psychology \\ Thesis Advisor \\ Dr. Marcus E. Sharpe
}

Portland State University 
Khajavei, 2

\section{Table of Contents}

$\begin{array}{lr}\text { Abstract } & 3\end{array}$

$\begin{array}{ll}\text { Personal connection } & 4\end{array}$

$\begin{array}{ll}\text { Intro } & 5\end{array}$

$\begin{array}{ll}\text { Barriers to female participation } & 7\end{array}$

Gender roles

Lack of early exposure and skill development

Gendered geographic fear

Current coping mechanisms

Moving forward

Closing Thoughts

References 
Khajavei, 3

\begin{abstract}
This literature review discusses the obstacles that women face in participating in outdoor recreation, the ways in which they are currently navigating these obstacles, and discusses how the current literature -- and the gaps within it -- can inform our future research and policy making. The obstacles women currently face in wilderness recreation surround gender roles and social expectations, lack of early skill-development and confidence, and a gendered geographic fear. Currently, women are navigating these obstacles by either conforming or rejecting gender roles in their participation, choosing to develop skills in female-only environments, and taking means to increase perceived safety such as carrying weapons and avoiding recreating outdoors alone. I argue that many of the ways in which women are currently navigating these issues take away from the initial draw of outdoor recreation. This research ends with a call for more research and some advice for future programs that encourages all-female elements, redefined leadership roles, reduced use of heavy stress and exhaustion for skill development, and with better advocation for safety measures and declaration of potential threats in a given activity.
\end{abstract}


Khajavei, 4

\section{PERSONAL CONNECTION}

As a young woman growing up in the Pacific Northwest, outdoor recreation was a huge part of my development. In my youngest years, I spent most of my time outside getting dirty, falling down, and pushing the limits of my own physical capabilities. These experiences defined me and shaped my confidence as I grew older. Throughout my early adulthood, through academic stresses, financial strife, and adolescent heartbreaks, the wilderness was more than just an escape from my obligations - it was a constant reminder of my capacity for self-reliance and independence. These feelings of competency have permeated my life beyond the environment in which I gained it, and help me to feel adequate and capable in all my interactions and endeavors. As I've continued to grow older and observe how my peers interact with the outdoor realm I've noticed a very gendered response. I've seen men interrupt a woman who knows what she's doing, I've seen women shy away from learning a new skill for fear of embarrassing themselves, and I've seen men exclude women from outdoor recreation simply under the assumption that they would have no interest.Meanwhile, and often without male presence, I've seen other female friends climb mountains, raft whitewater rivers, teach men survival skills, and hunt wild animals. These interactions have left me with a few questions: What obstacles do women face in participating in outdoor recreation? For the women who are participating, what are they doing to overcome these barriers? And most importantly, how can we design future programs to create space for women in the wilderness realm and encourage participation? 
Khajavei, 5

\section{INTRODUCTION}

Through a review of the current literature, I hope to answer these questions and provide guidance for future program development. Although women's participation in this realm has grown (Little, 2002), they are still vastly underrepresented in wilderness recreation (Henderson, 1995). This is, of course, very unfortunate given the many physical and mental health benefits of outdoor recreation. Outdoor recreation can decrease risk of cardiovascular disease (currently the number one cause of death for women, nearly doubling cancer-related deaths (Robertson, 2001)), decrease obesity, improve immune systems, and increase life expectancy (McNiel, Harris \& Fondren, 2012). Further, mental wellbeing benefits include reduced depression (women make up nearly two thirds of individuals with diagnosed depression (Strickland, 1992)), stress relief, improved quality of life, higher self-esteem, higher life satisfaction, tranquility, and a greater feeling of belonging (Bedimo-Rung, Mowen, \& Cohen 2005). Further, the existing studies surrounding female outdoor recreation indicate that these benefits may even be greater for women than for men and can drastically feelings of empowerment and self-reliance in women specifically (Ross, 2003; Autry, 2001). If women who recreate outdoors experience all these benefits, why are women still participating at a lower rate than men?

Current literature provides a few theories that serve as a jumping point for further understanding. My discussion will focus primarily on three barriers to women's participation in the outdoor realm that appeared continuously throughout the literature. The first obstacle discussed is the historically male-dominated nature of the outdoor realm and the gender roles that have developed from this. Along with this, media representations will be discussed as "an agent in the gender socialization process" (McNiel et al. , 2012). Second, this gendered exclusion leads 
Khajavei, 6

to a lack of early exposure to the outdoors that further influence the ways in which women interact with the wilderness. Lack of exposure contributes to overall feelings of self-doubt and fear that many women are taught associate with the vulnerability of the outdoors. Finally, these social pressures to conform to gender roles, and assumptions that the outdoor realm is not safe for women, creates a gendered geographic fear that further limits female participation.

What's also important to an understanding of this issue is an awareness that some women are participating despite these obstacles. How are they developing skills in a non-competitive and comfortable environment? What are they doing to overcome imposed gender roles? What are they doing to navigate gendered fear? Research indicates that overall, women are either conforming to gender roles by packing their femininity with them into the wilderness, or by defying gender roles entirely. When it comes to navigating fear, women seem to be taking a variety of safety measures. Primarily, women are recreating less alone than, carrying weapons with them, and communicating more about their whereabouts and plans than their male counterparts.

The existing research illustrates that women still crave outdoor experiences despite their obstacles and can benefit as much as -- or potentially more than -- their male counterparts. The surveying methods used by previous researchers are effective in illuminating obstacles and coping mechanisms for their specific demographic or setting, but an in-depth review of the literature is necessary in order to draw out common themes and gain a well rounded image of the whole picture. I argue that it is a mosaic of all these factors that contribute to the gendered wilderness experience, and that understanding these obstacles, along with understanding the ways that women are currently navigating them, is key to encouraging female participation in the 
future. I also argue that, based on this research, female-oriented programs need to include a de-emphasis of physical and psychological stress, a redefining of leadership roles, and should consider female-only participation.

\section{BARRIERS TO FEMALE PARTICIPATION IN OUTDOOR}

\section{RECREATION}

Current literature suggests that women lack a sense of claim to public outdoor spaces (Culp, 1998; Virden \& Walker, 1999; Wearing \& Wearing, 1998). The historic male-domination of the public and outdoor realms has created gender roles and societal expectations which limit and control the ways in which women interact with one another, with other genders, and with their environment. These roles, expectations, and relationships, then influence the opportunities and skill development accessible to women. A lack of outdoor skills and experience translates to a lack of confidence and comfort with these activities. All of these factors work together to create a gendered geographic fear that further limits women's comfort with participation in these worlds.

\section{Gender roles}

Historically, participation in athletics has been deeply associated with -- and exclusive to -- the masculine identity (Martin, 2004). Although it would be convenient to defer the gender-based differences and historically male dominated aspect of outdoor recreation to physical anatomy, that assumption would be deeply misguided. In fact, these differences do not stem from anatomical or biological differences -- their sources are "culturally constituted, or moulded" ideas of feminine and masculine behaviors (Connell, 1987). Wilderness recreation has 
been inculcated with heteronormativity and this heterosexualization of nature is dependent upon social constructions of what is "normal" behavior in activities for men and women (McNeil, 2012). This phenomenon begins in very young children and is passed down through socialized gender roles cemented in adolescence and works to limit and control both men and women through perceived expectations. Research indicates that by age five, both boys and girls have strictly defined gender roles that indicate appropriate behavior for themselves (Eccles 1987).

Although gender roles limit the behaviors of both genders, these constraints are certainly not evenly distributed in this sphere. In the realm of leisure, women and other members of the non-dominant group are disproportionately limited in their behaviors (Jackson, 2005; Jackson and Henderson; 1995). Tied closely with -- and as a result of -- these gender roles are expectations of feminine actions and appearances that often limit participation in traditionally masculine recreation. Female participants in a study conducted by Russell, C. L., Sarick, T., \& Kennelly, J. (2002) reported feelings of concern with accumulating labels such as "amazon", "lesbian" or "butch" associated with losing their feminine body image. As women avoid this realm in fear of being labeled "less-than-feminine", they create no role models for others that could encourage participation. The lack of females represented in leadership and outdoor roles then leads women to believe that not only are their not already women in these roles, but that these roles don't have space for them (McNeil, 2012). This leaves women who could be interested with little guidance and further reinforces the idea that the outdoor sphere is not for them (McNiel et al. , 2012).

The issues surrounding women and domesticity are especially notable in advertisements, and particularly in advertisements displaying outdoor leisure. Products related to wilderness 
recreation make up a $\$ 400$ million market (McNiel et al. , 2012). The vast majority of this media portrays women as inactive participants in outdoor recreation or implies a transfer of -- or need for escape from -- the private, domestic domain into the outdoor one. While advertisements of men recreating outdoors tend to illustrate the wilderness as a place for adventure and growth, the $46 \%$ of advertisements that include women paint a picture of relaxation and an "escape from to do lists and responsibilities" (McNiel et al. , 2012). Women in these advertisements are often shown having very low engagement in their environments compared to their male counterparts. Further, when women were shown recreating outdoors alone or participating in high-engagement or physical activities, they were displayed as "unordinary", or "unlike the average woman" (McNiel et al. , 2012). This further emphasizes a point that women are not meant for adventure, and those who seek it and enjoy it are out of the ordinary.

\section{Lack of early exposure and skill development}

As a another facet of these gender roles, young boys are encouraged to perform masculinity through use of their body in forceful ways, while girls are taught to "circumcise movements and limit their strengths" (Whitson, 1994). Young females are given very few opportunities to harness skills in the outdoor and athletic realm. This lack of exposure at a young age doesn't supply women with the skills and self-perceived confidence to seek out and enjoy these skills later in life (Bialeschki, Krehbiel, \& Henderson, 2002). Further, this lack of early skills and confidence development can lead women to be even more susceptible to the sexist and harassing remarks that Jessica Dooley's (2016) interviewees cited as one of the most frequently occurring obstacles they face in entering the outdoor realm as leaders. This perpetuates a feeling 
of exclusion for women working or participating in wilderness therapy programs and recreating outdoors.

This process snowballs throughout child development and continues to influence the ways in which different genders interact with one another and the world around them. This socialization process creates a fallacy in which both boys and girls -- and in turn, adult men and women -- believe that females are less capable both physically and at critical thinking than their male counterparts (Bialeschki, Krehbiel, \& Henderson, 2002). Unfortunately, even girls who are confident and eager participants in sports and outdoor activities as pre-adolescents typically stop participating as they grow older due to a loss of confidence in their physical capabilities (Pipher, 1994). This means that even the young girls who have an interest in outdoor recreation, have the resources to participate, and feel confident doing so, often do not carry this with them into adulthood. Once again, this leads to fewer adult female role models and encourages another generation of women who feel they do not belong in the outdoor realm.

\section{Gendered geographic fear}

Along with this exclusion and concern of negative appraisal, women also navigate a fear of violence and victimization in both urban and outdoor environments. In interviews conducted at South Mountain Park in Phoenix, Arizona, the fear described by women did not stem from nature itself, or isolation from urban areas -- it was a fear of human infringement and physical/sexual violence (Wesely \& Gaarder, 2004). Historically, women have not been taught to be comfortable or feel safe in the outdoor public sphere. Instead, they have been raised to view the private and domestic sphere as their domain (Wesely \& Gaarder, 2004). The fear of violence that women experience has been shown to greatly limit women's geographic mobility and 
interviews revealed that women named this factor the most when discussing their concerns with participation (Mcneil, 2012). Wesely (2004) also concludes that many women report constantly being hyper aware of their surroundings when recreating outdoors, and being hesitant to do so alone or with only female companions. Not surprisingly, female respondents perceived the outdoors as significantly less safe than male respondents (Mcneil, 2012). What's interesting about this is that the vast majority of crimes against women occurs within the private sphere (Wesely \& Gaarder, 2004). The geographic fear that women experience is one that is taught to them regardless of and in contradiction to where crime occurs and can drastically decrease the extent to which women seek out and enjoy activities taking place in green spaces both in and out of the city.

Further, these feelings of discomfort and fear in public/outdoor spaces are especially prevalent and rape/sexual assault-centric in women living in urban settings (Wesely \& Gaarder, 2004). This is unfortunate because these are the women that could potentially benefit most from a break from the stresses of urban life. Urban green spaces are important for the wellbeing and happiness of those living in urban environments (Daniel \& Meitner, 2001). The presence of these spaces provides aesthetic experiences, opportunity for recreation and provide relief from stress and mental fatigue (Sreetheran \& Van Den Bosch, 2014). However, despite the presence of urban green spaces in an effort to bring life to an urban environment, $61 \%$ of women living in the 26 largest U.S. cities reported feeling very or somewhat unsafe and ranked green spaces as one of the most dangerous places in a city; second only to alleys (Wesely \& Gaarder, 2004).

When it comes to green spaces within the city, it appears their use is just as gendered as natural green spaces. Females report significantly higher rates of fear and anxiety of urban green 
spaces than their male counterparts (Wesely \& Gaarder, 2004). What is helpful about studying urban green spaces is that, because they are man-made, we can effectively measure which features of these spaces causes women the most discomfort and use this as a way of understanding what exactly makes women uncomfortable in green spaces. This information can be helpful in designing future urban green spaces to be more inclusive, and can also help emphasize points of importance in programs aiming to help women feel more at ease in the wilderness.

\section{CURRENT COPING MECHANISMS}

Despite the many barriers to participation, women are still participating in outdoor recreation in high numbers (McNiel et al. , 2012). As mentioned, current research indicates that women are navigating gender roles in wilderness settings by either actively conforming or boldly defying gender roles in their participation with various mechanisms. Further, women are taking measures to increase perceived safety by carrying weapons and recreating with others

In regards to gender roles, women seem to be reacting in confliction ways. Some literature cites gender nonconformity as a coping mechanism while others cite feminizing the wilderness for the same purpose (Dooley, 2016; Bell, 1996). Many women cited that they often behave in more stereotypically masculine ways in the presence of males in an effort to demonstrate their capability (Dooley, 2016). For example, Dooley’s (2016) research at a an outdoor recreation camp notes that many women made a point to carry heavier objects, take out the trash, use vulgar language and discuss bodily functions a way of denying traditional gender roles and asserting their power in a male-dominated sphere. 
This same research also indicated the exact opposite phenomenon (Dooley, 2016). While some women chose to boldly defy gender norms, others refused to sacrifice their femininity in order to gain respect from them male counterparts. Women discuss wearing makeup while recreating outdoors despite feeling judged by men, using uniform bandanas in different and styling ways, and experimenting with hairstyles as a way of maintaining their feminine identity (Dooley, 2016). These behaviors may indicate a sense that women are pressure to conform to beauty standards in any environment, but can also be interpreted as a protest of the idea that women need to be masculine in order to survive in this environment.

Along with historical exclusion and gender stereotypes, women also navigate a fear of violence and victimization in both urban and outdoor environments. However, Wesely's (2004) surveys indicated that women felt significantly safer when recreating with others and often used this as a coping mechanism (See Table 1). Other coping mechanisms found throughout these surveys included recreating with dogs, bringing weapons with them while recreating, and being mindful of letting others know where they are/carrying cellphones at all times (Wesely \& Gaarder, 2004). 
Khajavei, 14

TABLE 1: How Respondents Felt When Recreating Alone and When Recreating with Others

\begin{tabular}{|c|c|c|c|c|c|c|}
\hline & \multicolumn{3}{|c|}{ Recreating Alone } & \multicolumn{3}{|c|}{ Recreating with Others } \\
\hline & $M^{a}$ & SD & $\mathrm{n}$ & $M$ & SD & $\mathrm{n}$ \\
\hline In control ${ }^{b}$ & 3.82 & 0.99 & 117 & 4.39 & 0.94 & 114 \\
\hline Comfortable $^{b}$ & 3.79 & 1.22 & 117 & 4.74 & 0.60 & 117 \\
\hline Safe from others ${ }^{b}$ & 3.47 & 1.06 & 116 & 4.42 & 0.89 & 113 \\
\hline Concerned $^{\mathrm{b}}$ & 3.12 & 1.18 & 119 & 2.24 & 1.22 & 113 \\
\hline Afraid $^{b}$ & 2.45 & 1.13 & 119 & 1.92 & 1.09 & 111 \\
\hline
\end{tabular}

a. Measured on a scale wherein $1=$ strongly disagree and $5=$ strongly agree.

b. Significant differences exist between recreating alone and recreating with others $(p<.001)$.

Wesely, J. K., \& Gaarder, E. (2004). The gendered "nature" of the urban outdoors women negotiating fear of violence. Gender \& Society, 18(5), 645-663.). How Respondents Felt When Recreating Alone and When Recreating with Others.

However, most of these methods take away from the benefits that women claim to be seeking out. Women describe some of the key reasons they seek out nature experiences is for isolation, quiet, and relaxation (Shellman, 2014). If women choose to alleviate anxiety and fear of violence by bringing a companion, they miss out on the isolation and self-reliance that they desire. If they venture out solo, they must sacrifice a peace of mind because they feel they must be constantly monitoring their environments for threats. The surveys conducted at South Mountain Park reveal that many women experience and ongoing battle between feeling safer with others but losing solitude and quiet (Wesely \& Gaarder, 2004). This creates a double edged sword for women seeking out wilderness experiences, and further limits their propensity towards participation. 
Khajavei, 15

\section{MOVING FORWARD}

All of the barriers that women face, along with the ways that they navigate them, are crucial to the development of programs that can help encourage women's use of outdoor space. Throughout the literature there were quite a few emerging themes surrounding this discussion and touching on all the obstacles previously discussed.

The first obstacle listed surrounded the gendered nature of the outdoor realm and the gender roles and expectations that women of all ages experience. Unfortunately, no program can undo the understanding of one's place that women are systemically and historically told is the domestic world. Given this, current methods of fighting gender exclusion can only start at the second stage which would mean to increase and improve the skills and experience provided to young women. I argue that fighting the theoretical and historical framework that created this divide, we can actively teach outdoor recreational skills and appreciate to women, and the surrounding attitudes will follow suit in due time. This is, of course, a very huge task in itself.

One of the most common solutions the literature provided for this was the implementation of an all-female program. A study done in 1998 by Rocklynn H. Culp conducted interviews with 55 girls, adolescent females, and adult women, to highlight key features for future programs and compare these findings to the existing literature. Their results indicated that many women would feel significantly more comfortable when developing skills only in the presence of other females. This was a reoccurring theme throughout much of the literature I explored and most sources provided slightly varying explanations for it's effectiveness. However, most studies indicated that this preference for all female programs stemmed from a desire to avoid the competition and intimidation that was experience in mixed-gender groups 
(Wilson, 2004; Culp, 1998). Another explanation provided was a freedom from pressure to conform to gender roles (Bialeschki \& Henderson, 1993).

Another important factor in improving programs, is the kind of leadership and facilitation present. Leaders in women's outdoor recreation play a very important role in addressing the fear and discomfort that many women feel in this realm. Leadership currently employed by most programs is oriented towards men, and is not conducive with the ways that women and girls learn (Bialeschki et al., 2002). Women tend to be less receptive to authoritative leaders (Bialeschki et al., 2002), so I propose the leadership styles in wilderness programs for women could benefit from co-facilitation.

Further, leadership with an emphasis on physical and psychological distress can be distressful and unproductive for female participants (Bialeschki et al. , 2002). Especially in programs oriented towards women with less developed outdoor skills, this should be avoided in order to encourage a sense of comfort in this environment and diffuse geographic fear already associated with this realm. Other studies indicate that women are much more comfortable when given clear language about the risk involved in a situation and when provided with a few, basic, safety tips (Jordan, 1992; Mitten, 1994). Keeping this in mind, programs could benefit from giving information to participants about the risks at hand and having a discussion about potential ways to navigate this risk before introducing them to the environment. Some scholars even suggest that this could be useful in the form of more educational and safety-oriented signage on trailheads (Bialeschki et al. , 2002). I would argue that this may also be an effective tactic when introduced to urban green spaces. 


\section{CLOSING THOUGHTS}

Current literature certainly serves as an excellent starting point for future progress.

However, there are connections still yet to be made between the fields of feminism, psychology, ecology, and the many others that are closely tied with this subject. As research improves, implications of an increase of female participation in the outdoor realm could drastically improve the lives of women, as well as society as a whole. In an effort to change the underlying attitudes and systemic sexism surrounding this issues, I argue that we must first change the minds and hearts of women starting at a much younger age where gender roles are slightly less limiting than adolescents and adulthood. As discussed, women benefit from outdoor recreation and experience a wide-range of mental and physical health benefits, but if we can use this realm as a means of addressing much larger issues of sexism and gender roles in our society, the implications are even greater. 


\section{References}

Anderson, L.M., Stokes, G.S., 1989. Planting in parking lots to improve perceived attractiveness and security. Journal of Arboriculture 15, 7-10.Bartky, S. 1990. Femininity and domination. New York: Routledge.

Angell, J. (1994). The wilderness solo: An empowering growth experience for women. Women \& therapy, 15(3-4), 85-99.

Anthonissen, L. (2011). An exploration of the gendered discourse in the talk of female facilitators of a wilderness programme (Doctoral dissertation, Stellenbosch: University of Stellenbosch).

Autry, C. E. (2001). Adventure therapy with girls at-risk: Responses to outdoor experiential activities. Therapeutic Recreation Journal, 35(4), 289.

Bialeschki, M. D., \& Henderson, K. A. (1993). Expanding outdoor opportunities for women. Parks \& Recreation (Arlington), 28(8), 36-40.

Bialeschki, M. D., Krehbiel, A., \& Henderson, K. A. (2002, January). Outcomes of camping: Perceptions from camper focus groups. In Proceedings of The Coalition for Education in the Outdoors Sixth Biennial Research Symposium (pp. 147-156).

Bedimo-Rung, A., Mowen, A., \& Cohen, D. (2005). The significance of parks to physical activity and public health. American journal of preventative medicine, 28, 159-168.

Bell, M. (1996). Feminists Challenging Assumptions about Outdoor Leadership.

Bordo, S. 1993. Unbearable weight. Berkeley: University of California Press. 
Cole, E., Erdman, E., \& Rothblum, E. D. (1994). Wilderness therapy for women: The power of adventure (Vol. 15, No. 3-4). Psychology Press.

Connell, R. W. (1987). Gender and power Cambridge. Polity, 279-304.

Culp, Rocklynn H. "Adolescent girls and outdoor recreation: a case study examining constraints and effective programming." Journal of Leisure Research, vol. 30, no. 3, 1998, p. 356+. General OneFile, Accessed 9 May 2017.

Daniel, T.C., Meitner, M.J., 2001. Representational validity of landscape visualizations: the effect of graphical realism on perceived scenic beauty of forest vistas. Journal of Environmental Psychology 21, 61-72.

Dooley, J. (2016). Young, Wild, and Female: Gendered Experiences at an Outdoor Adventure Camp.

Eccles, Jacquelynne S. "Gender roles and women's achievement-related decisions." Psychology of women Quarterly 11.2 (1987): 135-172.

Fletcher, T. B., \& Hinkle, J. S. (2002). Adventure based counseling: An innovation in counseling. Journal of Counseling and Development: JCD, 80(3), 277.

Gass, M. A., Gillis, L., \& Russell, K. C. (2012). Adventure therapy: Theory, research, and practice. Routledge.

Henderson, K. (1995). Marketing recreation and physical activity programs for females. Journal of Physical Education, Recreation, and Dance, 66, 53-57.

Hollander, J. A. (2001). VULNERABILITY AND DANGEROUSNESS The Construction of Gender through Conversation about Violence. Gender \& society, 15(1), 83-109. 
Hovey, K., Foland, J., Foley, J. T., Kniffin, M., \& Bailey, J. (2016). Predictors of Change in Body Image in Female Participants of an Outdoor Education Program. Journal of Outdoor Recreation, 8(2), 200-208.

Hornibrook, T., Brinkert, E., Parry, D., Seimens, R., Mitten, D., \& Priest, S. (1997). The benefits and motivations of all-women outdoor programs. Journal of Experiential Education, 20, $152-158$.

Jordan, D. (1992). Effective leadership for girls and women in outdoor recreation. Journal of Physical Education, Recreation, and Dance, 63, 61-64.

Kramer, L. 2001. The Sociology of Gender. Los Angeles: Roxbury

Levine, D. (1994). Breaking through barriers: Wilderness therapy for sexual assault survivors. Women \& therapy, 15(3-4), 175-184.

Little, D. E. (2002). Women and adventure recreation: Reconstructing leisure constraints and adventure experiences to negotiate continuing participation. Journal of Leisure Research, $34,157-177$.

Meyer, A. M. (2010). Gender, Body, and Wilderness: searching for refuge, connection, and ecological belonging.

McNiel, J. N., Harris, D. A., \& Fondren, K. M. (2012). Women and the wild: Gender socialization in wilderness recreation advertising. Gender Issues, 29(1-4), 39-55.

Mitten, D. (1994). Ethical considerations in adventure therapy: A feminist critique. In E. Cole, E.

Erdman, \& E. D. Rothblum (Eds.), Wilderness therapy for women: The power of adventure (pp. 55-84). New York: Hawthorne.

Martin, E. 1992. The woman in the body. Boston: Beacon. 
Martin, D. C. (2004). Apartheid in the great outdoors: American advertising and the reproduction of a racialized outdoor leisure identity. Journal of Leisure Research, 36(4), 513.

Norton, C. L., \& Hsieh, C. M. (2011). Cultural bridging through shared adventure: cross-cultural perspectives on adventure therapy. Journal of Adventure Education \& Outdoor Learning, 11(2), 173-188.

Pohl, S. L., Borrie, W. T., \& Patterson, M. E. (2000). Women, wilderness, and everyday life: A documentation of the connection between wilderness recreation and women's everyday lives. Journal of Leisure Research, 32(4), 415.

Powch, I. G. (1994). Wilderness therapy: What makes it empowering for women?. Women \& Therapy, 15(3-4), 11-27.

Robertson, R. M. (2001). Women and cardiovascular disease.

Ross, S. (2003). The therapeutic effects of an adventure challenge program on the personal empowerment of women survivors of sexual trauma. The Journal of Experiential Education, 25(3), 350 .

Russell, C. L., Sarick, T., \& Kennelly, J. (2002). Queering environmental education. Canadian Journal of Environmental Education, 7, 54-66.

Scarborough, B.K., Like-Haislip, T.Z., Novak, K.J., Lucas, W.L., Alarid, L.F., 2010. Assessing the relationship between individual characteristics, neighborhood context, and fear of crime. Journal of Criminal Justice 38, 819-826.

Sreetheran, M., \& Van Den Bosch, C. C. K. (2014). A socio-ecological exploration of fear of crime in urban green spaces-A systematic review. Urban Forestry \& Urban Greening, 13(1), 1-18. 
Strickland, B. R. (1992). Women and depression. Current Directions in Psychological Science, 1(4), 132-135.

Virden, R., \& Walker, G. (1999). Ethnic/racial and gender variations among meanings given to, and preferences for, the natural environment. Leisure Sciences, 21, 219-239.

Wearing, B., \& Wearing, S. (1988). "All in a day's leisure”: Gender and the concept of leisure. Leisure Studies, 7, 111-123.

Wesely, J. K., \& Gaarder, E. (2004). The gendered "nature" of the urban outdoors women negotiating fear of violence. Gender \& Society, 18(5), 645-663.

Whitson, D. (2002). 15 The embodiment of gender: Discipline, domination, and empowerment. Gender and sport: A reader, 227.

Wilson, L. (1994). Iowa's becoming an outdoors-woman: Workshop report. Iowa Dept. of Natural Resources. 